\title{
Matrine induces apoptosis in acute myeloid leukemia cells by inhibiting the PI3K/Akt/mTOR signaling pathway
}

\author{
YANMEI HAO $^{1 *}$, NAN ZHANG $^{1 *}$, NANNAN WEI $^{2 *}$, HONGMEI YIN $^{2}$, \\ YINGJIE ZHANG ${ }^{1}$, HUI XU ${ }^{1}$, CHAOMANG ZHU ${ }^{2}$ and DUOJIE LI $^{2}$ \\ ${ }^{1}$ Department of Clinical Laboratory, Bengbu Medical College; ${ }^{2}$ Department of Radiotherapy, \\ The First Affiliated Hospital of Bengbu Medical College, Bengbu, Anhui 233004, P.R. China
}

Received October 15, 2018; Accepted June 12, 2019

DOI: $10.3892 / \mathrm{ol} .2019 .10649$

\begin{abstract}
Matrine has been demonstrated to exert anticancer effects on acute myeloid leukemia (AML) cell lines. However, the mechanisms of matrine in AML remain largely unknown. The present study investigated the anticancer effects and underlying mechanisms of matrine on human AML cells in vitro. THP-1 cell lines were cultured and treated with different doses of matrine $(0.4,0.8,1.2,1.6$ and $2.0 \mathrm{~g} / \mathrm{l})$. The effects of matrine on the cell proliferation were assessed by the Cell Counting Kit- 8 assay. The apoptotic effects were evaluated by DAPI and annexin V/propidium iodide staining assays. The effects of the drug on phosphoinositide 3-kinase (PI3K)/protein kinase B (Akt)/ mechanistic target of rapamycin kinase (mTOR) protein expression were studied by western blot analysis. The results of the present study demonstrated that matrine suppressed the viability of THP-1 cells. The anticancer effects were identified to be dose-dependent and the $\mathrm{IC}_{50}$ value was $1.2 \mathrm{~g} / 1$ in THP-1 cells. Matrine inhibited cell viability and induced cell apoptosis of AML cell lines in a dose- and time-dependent manner. In addition, it was observed that matrine decreased the expression of phosphorylated (p)-PI3K, p-Akt and p-mTOR in a concentration-dependent manner. However, the expression levels of PI3K, Akt and mTOR remained almost unaltered. These findings indicated that matrine may inhibit cell proliferation and induce apoptosis of AML cells and may be a novel effective chemotherapeutic agent against AML.
\end{abstract}

Correspondence to: Professor Duojie $\mathrm{Li}$, Department of Radiotherapy, The First Affiliated Hospital of Bengbu Medical College, 287 Changhuai Road, Bengbu, Anhui 233004, P.R. China E-mail: liduojie@163.com

*Contributed equally

Key words: matrine, acute myeloid leukemia, phosphoinositide 3-kinase, protein kinase $\mathrm{B}$, mammalian target of rapamycin, signaling pathway

\section{Introduction}

Acute myeloid leukemia (AML) is a heterogeneous disease resulting from multiple genetic and epigenetic abnormalities that affect differentiation, proliferation and apoptosis of myeloid cells (1). The traditional treatment for leukemia is chemotherapy; however, chemotherapy has serious side effects and may result in treatment failure due to treatment-associated mortality or the emergence of drug resistance (2). Despite recent advances in treatment strategies, AML remains an incurable disease (3). In recent years, traditional Chinese medicine has been extensively used and has demonstrated success in the treatment of leukemia. For example, arsenic trioxide can achieve a high complete remission rate in the treatment of acute promyelocytic leukemia (APL) and is particularly effective for patients with recurrent APL (4-6).

Matrine, an alkaloid extracted from a Chinese herb, has been widely used to treat viral hepatitis, cardiac arrhythmia and skin inflammation, and exhibits chemotherapeutic potential through its ability to trigger caspase-independent programmed cell death (7). Matrine has also been demonstrated to exert potential activities against different types of leukemia by inhibiting cancer cell proliferation, accelerating apoptosis, inducing cell cycle arrest and suppressing metastasis $(8,9)$. A number of studies have reported that matrine inhibits AML cell proliferation via a variety of mechanisms, including cancer cell differentiation and apoptosis, altering the tumor cell cycle and inhibiting telomerase activity $(7,10,11)$.

The phosphoinositide 3-kinase (PI3K)/protein kinase B (Akt)/mechanistic target of rapamycin kinase (mTOR) signaling pathway is involved in cell growth, proliferation and differentiation, and serves important roles in tumor occurrence, development, treatment and outcome (9). A number of studies have reported that there is continuous activation of the $\mathrm{PI} 3 \mathrm{~K} / \mathrm{Akt} / \mathrm{mTOR}$ signaling pathway in leukemia cells $(12,13)$. However, to the best of our knowledge, a systematic scientific evaluation of matrine has not been performed for AML and its anticancer mechanisms on AML cell lines remain unclear. The present study investigated the anticancer activity of matrine in THP-1 cells and revealed an induction of apoptosis and inhibition of the PI3K/Akt/mTOR signaling pathway following treatment with matrine. 


\section{Materials and methods}

Chemicals and reagents. Human AML THP-1 cells were purchased from the Cell Bank of Chinese Academy of Sciences. Matrine was purchased from Tianyuan Biological Agent Plant. The Cell Counting Kit-8 (CCK-8) was purchased from Dojindo Molecular Technologies, Inc. RPMI-1640 medium, fetal bovine serum (FBS), dimethyl sulfoxide dissolving (DMSO), penicillin and streptomycin were purchased from Invitrogen; Thermo Fisher Scientific, Inc. The ELISA reader ELx800 was obtained from Bio-Tek Instruments, Inc. Inverted phase contrast microscope was obtained from Olympus Corporation. LY294002 was purchased from Cell Signaling Technology, Inc. and was dissolved in DMSO according to the manufacturer's instructions. Antibodies, including anti-PI3K, anti-phosphorylated (p)-PI3K, anti-mTOR, anti-p-mTOR, anti-Akt, anti-p-Akt and anti- $\beta$-actin were purchased from ABclonal Biotech Co., Ltd. The current study was approved by the Ethics Committee of Bengbu Medical College (Bengbu, China).

Cell culture. THP-1 cell lines were maintained in RPMI-1640 medium supplemented with $10 \% \mathrm{FBS}, 100 \mathrm{U} / \mathrm{ml}$ penicillin and $100 \mu \mathrm{g} / \mathrm{ml}$ streptomycin at $37^{\circ} \mathrm{C}$ with $5 \% \mathrm{CO}_{2}$. A total of $5 \times 10^{3}$ cells in $100 \mu 1$ RPMI-1640 medium were plated in 96-well plates. When the cell growth reached the log growth phase, the cells were treated with trypsin to obtain a single cell suspension, and were then seeded into different culture plates or dishes for subsequent experiments, according to the experimental requirements.

Morphology change. THP-1 cells, at a density of $2.0 \times 10^{5}$ cells/well, were equally seeded in 24 -well flat bottom microtiter plates at room temperature, and then treated with matrine at the concentration of $0,0.8,1.2$ and $1.6 \mathrm{~g} / \mathrm{l}$. After $24 \mathrm{~h}$ of treatment, the morphology of THP-1 cells was observed under an inverted phase contrast microscope (magnification, $\mathrm{x} 100)$.

Cell viability assay. THP-1 cells at a density of $2.0 \times 10^{5}$ cells/well were plated in 96-well microtiter plates and treated with various doses of matrine $(0,0.4,0.8,1.2,1.6$ and $2.0 \mathrm{~g} / \mathrm{l})$, dissolved in RPMI-1640 medium, for 12,24 and $48 \mathrm{~h}$ at $37^{\circ} \mathrm{C}$ with $5 \% \mathrm{CO}_{2}$. Cell viability was subsequently measured using the CCK-8 assay according to the manufacturer's protocol. Briefly, $20 \mu$ l CCK-8 solution was added to the culture medium $24 \mathrm{~h}$ following matrine treatment. The cells were incubated for $4 \mathrm{~h}$ at $37^{\circ} \mathrm{C}$. The absorbance was read at a wavelength of $450 \mathrm{~nm}$ using the ELx800 ELISA reader. All experiments were repeated a minimum of four times. The absorbance value was measured and the proliferation inhibition rate (IR) was calculated as: $\mathrm{IR}=$ (control group absorbance-experimental group absorbance)/control group absorbance $\times 100 \%$. The cell viability rate $(\%)=\mathrm{A} 450$ (matrine)/A450 (control) $\mathrm{x} 100 \%$.

Apoptosis assay. The ability of matrine to induce apoptosis in AML cells was assessed by Annexin V-fluorescein isothiocyanate (FITC)/propidium iodide (PI) double staining. AML cells were plated at a density of $2.0 \times 10^{5}$ cells/well in 6 -well plates. The cells were then treated with $0,0.8,1.2$ and $1.6 \mathrm{~g} / \mathrm{l}$ of matrine or $20 \mu \mathrm{mol} / 1 \mathrm{LY} 294002$, dissolved in DMSO, for $24 \mathrm{~h}$ or $1.2 \mathrm{~g} / \mathrm{l}$ matrine at $37^{\circ} \mathrm{C}$ for three different time points $(12,24$ and $48 \mathrm{~h})$. The cells in 6-well plates were stained with DAPI $(3 \mu \mathrm{M})$. The cells were then washed with PBS and fixed with $10 \%$ formaldehyde at room temperature for $20 \mathrm{~min}$. The DAPI-stained cells were observed with a fluorescence microscope (magnification, $\mathrm{x} 100)$ for estimation of the percentage of cells not undergoing apoptosis. After treatment, the cells were collected and stained at $25^{\circ} \mathrm{C}$ with Annexin V-FITC and PI using an Annexin V-FITC Apoptosis Detection kit (BD Biosciences). Subsequently, apoptosis analysis was performed using FITC signal detector (FL1) and PI signal detector (FL2) using a flow cytometer (BD Accuri C6) and analyzed using the FACSCalibur system (BD Biosciences). The apoptosis ratio of THP-1 cells contains the percentage of early-phase apoptotic cells and early-phase apoptotic cells. The experiment was repeated three times independently with similar results.

Western blot analysis. To further investigate whether the PI3K/Akt/mTOR signaling pathway is associated with the inhibitory effects of matrine in THP-1 cells, the PI3K-specific inhibitor LY294002 was used to treat THP-1 cells prior to western blot analysis. Following treatment with matrine or $20 \mu \mathrm{mol} / 1 \mathrm{LY} 294002$, changes in protein expression levels were detected using western blot analysis. THP-1 cells were collected from each group and total protein was extracted using radioimmunoprecipitation assay buffer (cat. no. P0013B; Beyotime Institute of Biotechnology; Haimen, China). Protein concentration was determined by the bicinchoninic acid assay. A total of $20 \mu \mathrm{g}$ protein was separated by SDS-PAGE on a $10 \%$ gel and then transferred to polyvinylidene fluoride (PVDF) membrane. The PVDF membrane was then incubated with anti-p-PI3K (dilution 1:1,000; cat. no. Ap0427), anti-PI3K (dilution 1:2,000; cat. no. A11177), anti-p-Akt (dilution 1:2,000, cat. no. AP0140), anti-Akt (dilution 1:2,000; cat. no. A11016), anti-p-mTOR (dilution 1:2,000; cat. no. AP0094), anti-mTOR (dilution 1:2,000; cat. no. A2445) or anti- $\beta$-actin (dilution 1:200,000; cat. no. AC026) (all from ABclonal Biotech Co., Ltd.) at $4^{\circ} \mathrm{C}$ overnight. Subsequently, the membrane was washed with washing buffer and incubated with secondary antibody goat anti-rabbit IgG (H+L) (1:3,000; cat. no. s0001; Beyotime Institute of Biotechnology) for $1 \mathrm{~h}$ at $25^{\circ} \mathrm{C}$. The protein bands were visualized by an ECL Advanced Western Blot Detection kit (EMD Millipore).

Statistics analysis. Statistical analysis was performed using SPSS software (version 17; SPSS, Inc., Chicago, IL, USA). Data are presented as the mean \pm standard deviation and are representative of at least three independent experiments. One-way analysis of variance followed by the Bonferroni correction was used to assess the differences among the groups treated with different doses of matrine. $\mathrm{P}<0.05$ was considered to indicate a statistically significant difference.

\section{Results}

Matrine inhibits the proliferation of AML cells. The effects of matrine or LY294002 on the proliferation of the AML cell line THP-1 cells were examined. Matrine inhibited the proliferation of THP-1 cells in a dose- and time-dependent manner, with a 

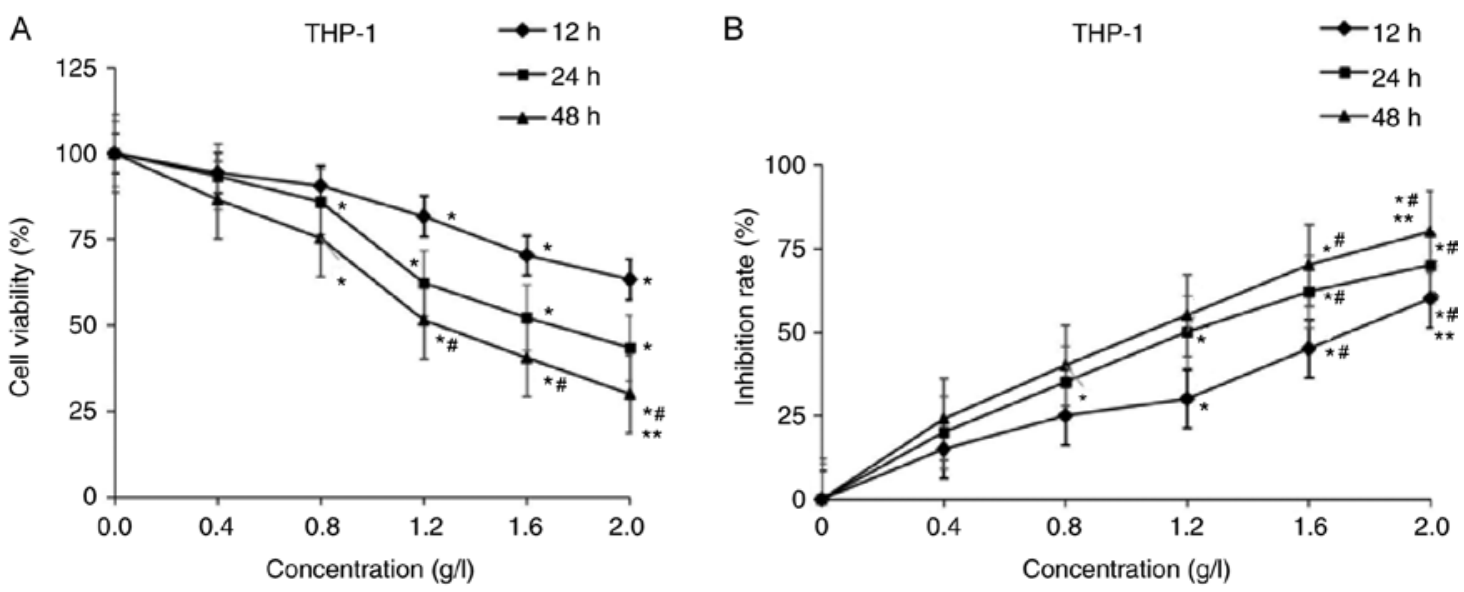

Figure 1. Effects of matrine on the proliferation of acute myeloid leukemia cells. THP-1 cells were treated with $0,0.4,0.8,1.2,1.6$ and $2.0 \mathrm{~g} / 1 \mathrm{matrine}$ for 12 , 24 and 48 h. Cell viability was assessed by a Cell Counting Kit-8 assay. (A) Cell viability rate. (B) Inhibition rate. Data are presented as the mean of at least three independent experiments. ${ }^{*} \mathrm{P}<0.05$ vs. $0 \mathrm{~g} / 1$ matrine; ${ }^{~} \mathrm{P}<0.05$ vs. $0.4 \mathrm{~g} / 1$ matrine; ${ }^{* * *} \mathrm{P}<0.05$ vs. $1.2 \mathrm{~g} / 1$ matrine.

half-maximal inhibitory concentration $\left(\mathrm{IC}_{50}\right)$ of $1.2 \mathrm{~g} / \mathrm{l}$ at $24 \mathrm{~h}$ (Fig. 1A). Following treatment with different doses of matrine, it was identified that matrine decreased the cell viability in a dose-dependent manner. The cell proliferation rates of the groups treated with $0.8,1.2,1.6$ and $2.0 \mathrm{~g} / 1$ matrine were significantly lower compared with the group treated with $0 \mathrm{~g} / \mathrm{l}$ matrine (treated with DMSO only) for 24 and $48 \mathrm{~h}(\mathrm{P}<0.05)$. The cell proliferation rates of the 1.6 and $2.0 \mathrm{~g} / \mathrm{l}$ matrine-treated groups were significantly lower compared with that of the $0.4 \mathrm{~g} / \mathrm{l}$ matrine-treated group for $48 \mathrm{~h}(\mathrm{P}<0.05)$. The cell proliferation rate of the $2.0 \mathrm{~g} / \mathrm{l}$ matrine-treated group was significantly lower compared with the $1.2 \mathrm{~g} / 1$ matrine-treated group for $48 \mathrm{~h}$ $(\mathrm{P}<0.05)$. Pair-wise comparisons of the cell proliferation activity were statistically significant among the groups treated with different doses of matrine ( $\mathrm{P}<0.05$; Fig. 1A). Compared with the $12 \mathrm{~h}$ group, the inhibitory rate of THP-1 cell proliferation of $48 \mathrm{~h}$ increased from 22 to $56 \%$ following exposure to $1.2 \mathrm{~g} / \mathrm{l}$ matrine $(\mathrm{P}<0.05$; Fig. 1B). Matrine decreased the proliferation of AML cells. In addition, during the prolonged treatments (24 and $48 \mathrm{~h}$ ), $1.6 \mathrm{~g} / 1$ matrine demonstrated a significantly greater inhibitory effect compared with that at $12 \mathrm{~h}(\mathrm{P}<0.05)$. Furthermore, matrine induced changes in the morphology of the AML THP-1 cells, such as the presence of autophagy vesicles (Fig. 2). The $\mathrm{IC}_{50}$ concentration of AML cells treated with matrine for $24 \mathrm{~h}$ was $1.2 \mathrm{~g} / \mathrm{l}$. These results indicated that matrine may exert its anticancer effects by decreasing the proliferation of AML cells and affecting their morphology.

Matrine induces apoptosis of AML cells. Compared with the blank control group, treatment with various concentrations of matrine $(0.8,1.2$ and $1.6 \mathrm{~g} / \mathrm{l})$ for $24 \mathrm{~h}$, significantly induced apoptosis of THP-1 cells (Fig. 3A). The apoptosis ratio for $24 \mathrm{~h}$ in the control group was $0.037 \pm 0.0012$, whereas the apoptosis ratios in the $0.8,1.2$ and $1.6 \mathrm{~g} / \mathrm{l}$-treated groups were $0.234 \pm 0.0011,0.412 \pm 0.0013$ and $0.485 \pm 0.0010$, respectively $(\mathrm{P}<0.05$; Fig. 3A and B). Compared with the control group, the apoptosis of THP-1 cells treated with $1.2 \mathrm{~g} / 1$ matrine for 12, 24 and $48 \mathrm{~h}$ was significantly increased. The apoptosis ratio in the control group was $0.039 \pm 0.0013$, whereas the apoptosis ratios in the groups treated for 12,24 and $48 \mathrm{~h}$ were $0.305 \pm 0.0010$,
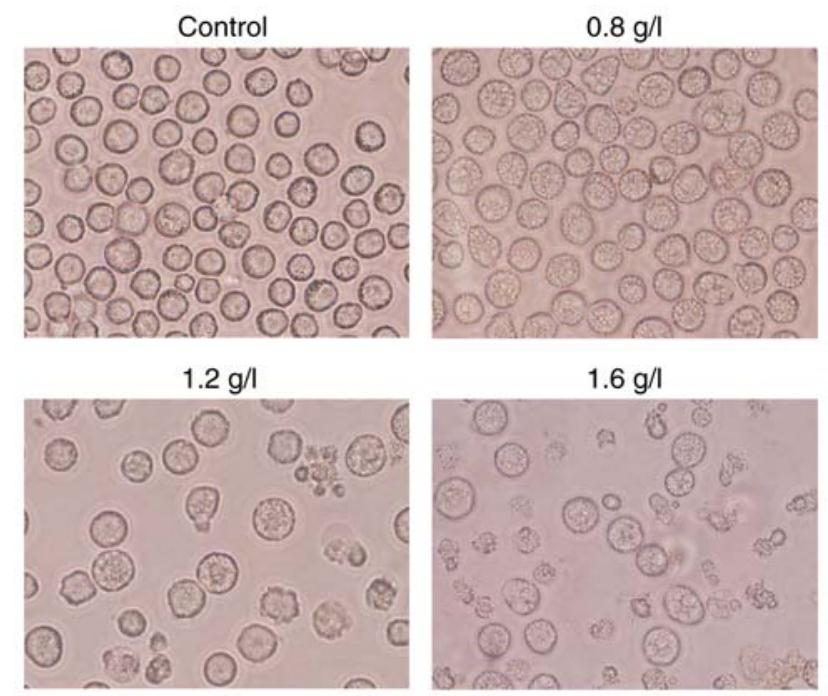

Figure 2. Effects of matrine on cell morphology observed using phase contrast microscopy. Matrine induced changes in the morphology of THP-1 cells, such as the presence of autophagic vacuoles, which indicates that the drug exerts cytotoxic effects in these cells. Magnification, x100.

$0.435 \pm 0.0015$ and $0.513 \pm 0.0012$, respectively $(\mathrm{P}<0.05$; Fig. 4A and B). The apoptosis ratio of THP-1 cells treated with $20 \mu \mathrm{mol} / 1 \mathrm{LY} 294002$ was similar to that of $1.2 \mathrm{~g} / 1$ matrine (Fig. 3B). The annexin V FITC/PI staining revealed that the apoptosis ratio increased in a dose- and time-dependent manner in the matrine-treated THP-1 cells.

Matrine inhibits the PI3K/Akt/mTOR signaling pathway. In the present study, the effect of matrine on the PI3K/Akt/mTOR signaling pathway was investigated. Matrine decreased the expression of $\mathrm{p}$-PI3K, $\mathrm{p}$-Akt and $\mathrm{p}$-mTOR in a concentration-dependent manner. The expression of $\mathrm{p}-\mathrm{PI} 3 \mathrm{~K}, \mathrm{p}-\mathrm{Akt}$ and $\mathrm{p}$-mTOR was higher in the $0 \mathrm{~g} / \mathrm{l}$ matrine-treated group compared with the groups treated with $20 \mu \mathrm{mol} / 1 \mathrm{LY} 294002$ or $1.2 \mathrm{~g} / 1$ matrine. However, no notable differences in the expression levels of PI3K, Akt and mTOR following treatment with matrine or $20 \mu \mathrm{mol} / 1$ LY294002 were revealed (Fig. 5). 
A

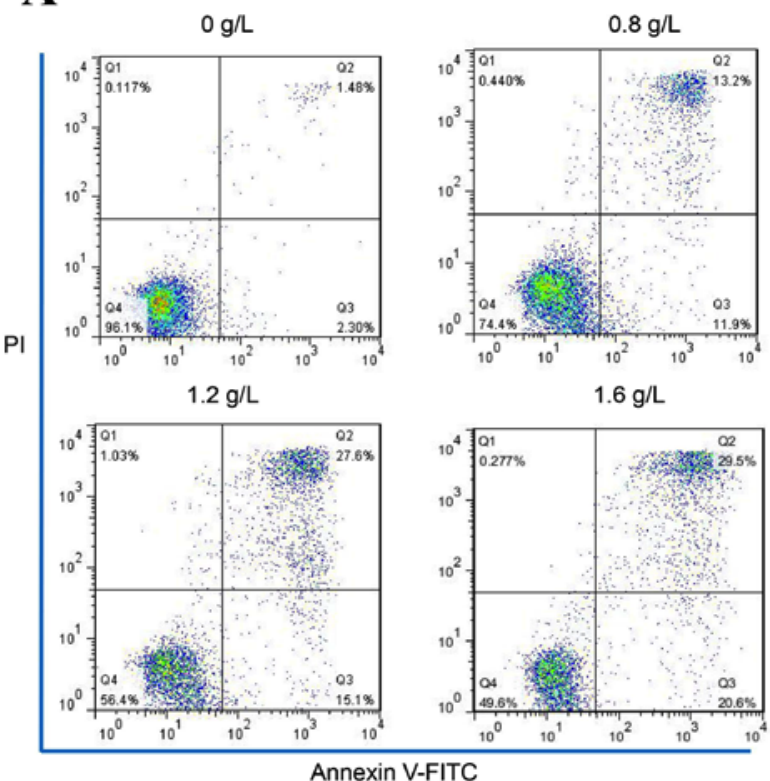

B

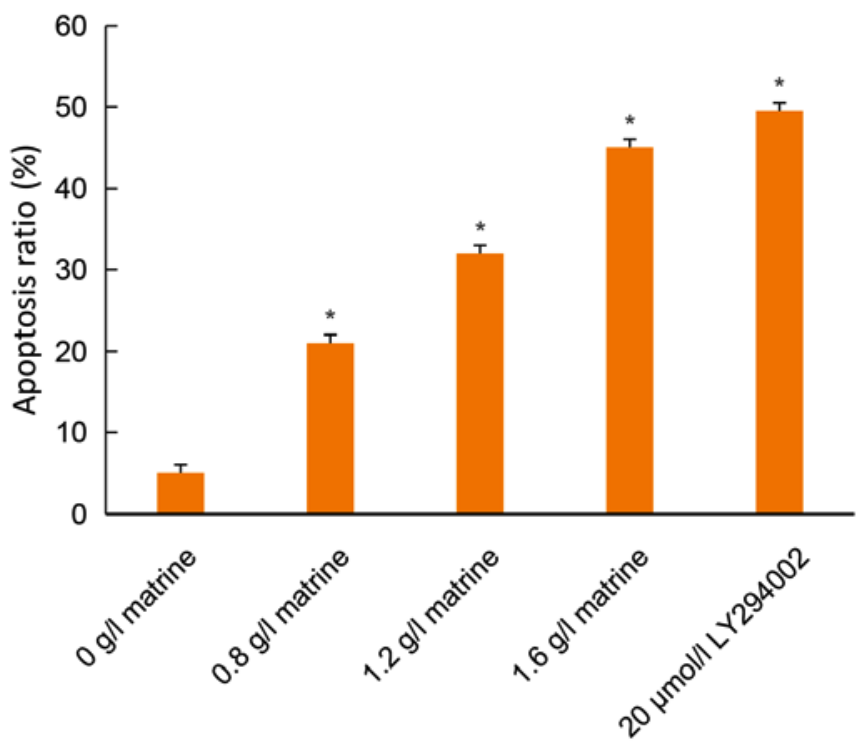

Figure 3. Matrine induces apoptosis in a dose-dependent manner. Annexin V-FITC/PI staining was performed to assess apoptosis. Annexin V-negative/PI-negative (lower left quadrant), Annexin V-positive/PI-negative (lower right quadrant), Annexin V-positive/PI-positive (upper right quadrant) and Annexin V-positive/PI-positive (upper left quadrant) cells were considered as the viable, early-phase apoptotic, late-phase apoptotic and necrotic cells, respectively. The percentage of cells is presented in each quadrant. (A) THP-1 cells. (B) Representative histograms of apoptosis of THP-1 cells induced by matrine or LY294002 are presented. "P<0.05 vs. the control. The data are presented as the mean \pm standard deviation of at least three independent experiments. FITC, fluorescein isothiocyanate; PI, propidium iodide.

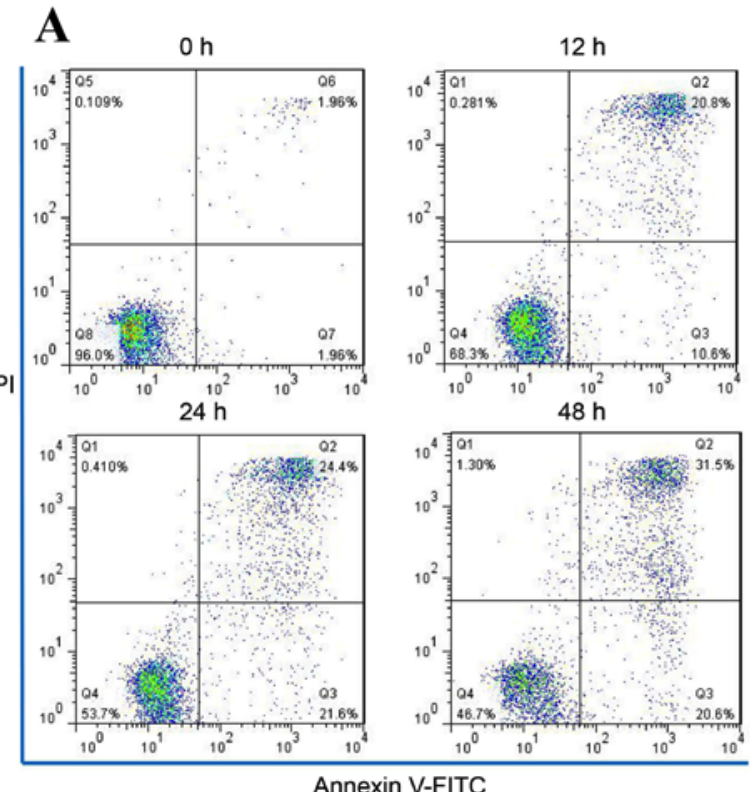

B

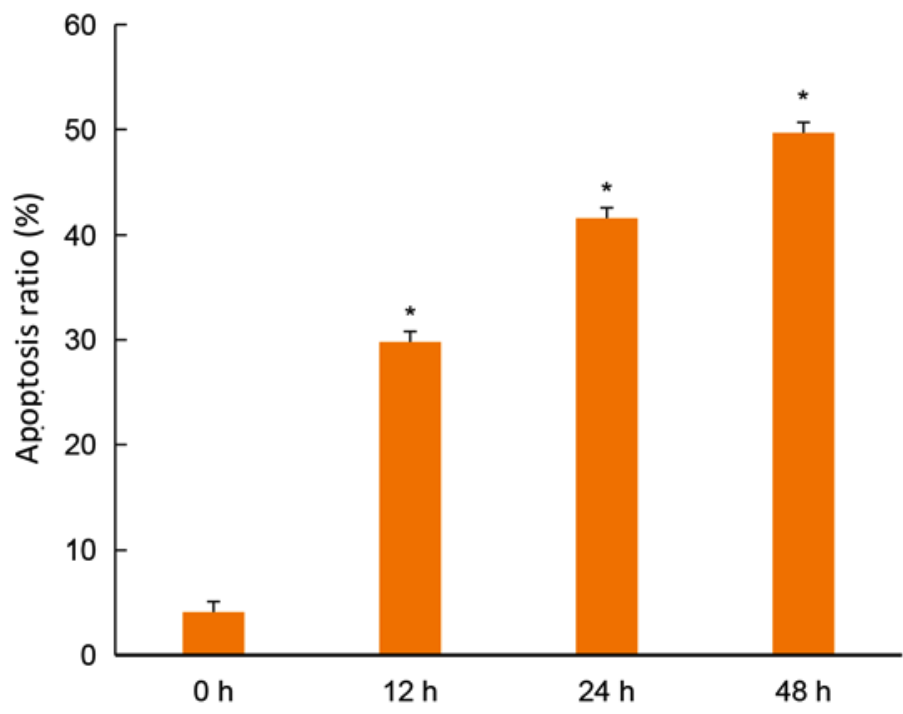

Figure 4. Matrine induces apoptosis in a time-dependent manner. Annexin V-FITC/PI staining was performed to assess apoptosis. Annexin V-negative/PI-negative (lower left quadrant), Annexin V-positive/PI-negative (lower right quadrant), Annexin V-positive/PI-positive (upper right quadrant) and Annexin V-positive/PI-positive (upper left quadrant) cells were considered as the viable, early-phase apoptotic, late-phase apoptotic and necrosis cells, respectively. The percentage of cells is presented in each quadrant. (A) THP-1 cells. (B) Representative histograms of apoptosis of THP-1 cells induced by matrine are presented. "P<0.05 vs. $0 \mathrm{~g} / 1$ matrine. The data are presented as the mean \pm standard deviation of at least three independent experiments. FITC, fluorescein isothiocyanate; PI, propidium iodide.

\section{Discussion}

AML is a type of tumor of the blood characterized by an abnormal increase of immature white blood cells (14). Due to the high toxicity and associated side effects of traditional chemotherapy agents commonly used in clinical practice, as well as the high recurrence rates, there is a requirement for the development of novel drugs (15). For decades, matrine, a traditional Chinese herbal medicine, has been demonstrated to possess cytoprotective effects and biological safety, and has been used in the treatment of 


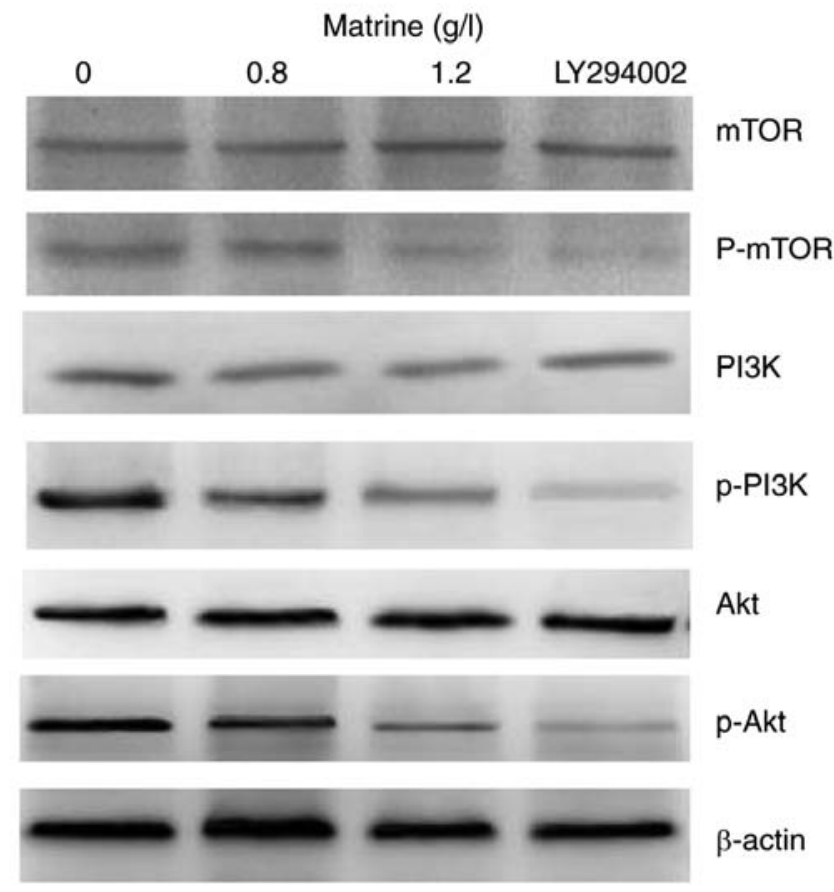

Figure 5. Various concentrations of matrine affect the expression of PI3K/AKT pathway-associated proteins in THP-1 cells. Western blotting was performed in triplicate. Matrine decreased the expression levels of p-PI3K, p-Akt and p-mTOR in a concentration-dependent manner. However, no differences were revealed in the expression levels of PI3K, Akt and mTOR following treatment with matrine. PI3K, phosphoinositide 3-kinase; Akt, protein kinase B; mTOR, mechanistic target of rapamycin kinase; $p$, phosphorylated.

a number of diseases, including hepatic fibrosis, atherosclerosis, arrhythmias and infectious diseases $(16,17)$. It has also been reported that matrine inhibits hepatocellular carcinoma and leukemia cell proliferation via various mechanisms, including inducing cancer cell differentiation and apoptosis, altering the tumor cell cycle and inhibiting telomerase activity $(7,10,11)$.

Uncontrolled proliferation is a key aspect of tumorigenesis and inhibiting cell proliferation arrests the growth of tumor cells $(9,16)$. To investigate the role of matrine in THP-1 cells, the present study first performed a cell viability assay, which revealed that matrine significantly inhibited THP-1 cell viability in a dose- and time-dependent manner. To observe the cytotoxicity of matrine, concentrations of $0,0.4,0.8,1.2,1.6$ and $2.0 \mathrm{~g} / \mathrm{l}$ matrine were selected for subsequent experiments. In the current study, the anticancer effects were identified to be dose-dependent and the $\mathrm{IC}_{50}$ value was determined as $1.2 \mathrm{~g} / 1$ in THP-1 cells. The cell viability results indicated that compared with the control, various concentrations of matrine significantly reduced the viability of THP-1 cells.

To further investigate the mechanisms underlying the anticancer effects of matrine, the present study performed DAPI staining and observed that matrine, may exert its anticancer effects via induction of apoptosis (data not show). It was demonstrated that matrine significantly increased the apoptosis of AML cells in vitro; the rate of apoptosis was $42.70 \%$ for $\mathrm{AML}$ cells treated with the $\mathrm{IC}_{50}$ concentration of matrine of $1.2 \mathrm{~g} / 1$ for $24 \mathrm{~h}$. Furthermore, the apoptotic effects of matrine were concentration-dependent and the apoptotic cell populations increased with an increase in the concentration of matrine, as demonstrated by annexin V/PI staining. It has previously been reported that matrine exerts its antitumor effects by inhibiting the proliferation and inducing the apoptosis of AML cells $(11,18,19)$. Consistent with these previous studies, the present study demonstrated that matrine induced AML cell apoptosis in a dose-dependent manner in the range of 0.4-2.0 g/l. Apoptosis is considered one of the important mechanisms that prevents the development of disease, including cancer, as abnormal cells are eliminated via this process (18).

Several signaling pathways such as PI3K/AKT or Notch regulate cell proliferation and apoptosis. Molecular biology studies have been instrumental in deciphering the pathogenesis of AML (13). The inhibition of signaling pathways, such as PI3K/AKT, are considered to be the most important factors in determining the response to chemotherapy and the outcome of AML $(20,21)$. The PI3K/Akt/mTOR signaling pathway is an important pathway that has been reported to be activated in several types of cancer (22-24). PI3K, a signaling protein with catalytic activity within cells, is activated by the action of extracellular cytokines, drugs, stress and other factors. Once activated, PI3K phosphorylates phosphatidylinositol $(4,5)$-bisphosphate to phosphatidylinositol $(3,4,5)$-trisphosphate, and promotes Akt activation to regulate the expression of a variety of cell proliferation-associated genes and other genes (12). It has been reported that patients with AML and hyperactivation of Akt signaling in AML cells exhibit a worse prognosis and shorter survival time compared with patients with normal levels of Akt activation $(25,26)$. Therefore, drugs targeting this pathway may prove useful in the treatment of different types of malignancy.

The present study investigated the effect of matrine on the expression of p-PI3K, PI3K, p-Akt, Akt, p-mTOR and mTOR. It was identified that matrine decreased the expression of p-PI3K, p-Akt and p-mTOR in a concentration-dependent manner, indicating that the anticancer effects of matrine may in part be due to inhibition of the PI3K/Akt/mTOR signaling pathway. In the current study, treatment with matrine inhibited the activity of PI3K and Akt in THP-1 cells, as demonstrated by a decrease in their phosphorylated levels, which lowers their downstream kinase activity and inhibits the pathway (19). To further clarify whether the PI3K/Akt signaling pathway is targeted and regulates the inhibitory effects of matrine in THP-1 cells, the PI3K-specific inhibitor LY294002 was used to treat THP-1 cells. The expression of p-PI3K, p-Akt and p-mTOR was markedly lower in the group treated with $20 \mu \mathrm{mol} / 1$ LY294002 compared with the control group. This further suggested that matrine-induced apoptosis may be attributed, at least partially, to PI3K/Akt inactivation. Similarly, previous studies have demonstrated that matrine suppresses the phosphorylation of Akt in AML THP-1 cells $(26,27)$. The identification of matrine as a novel Akt inhibitor may have implications for cancer biology and treatment.

In conclusion, the present study demonstrated that matrine exhibited anticancer effects in THP-1 cells in vitro. The anticancer activity of matrine may be attributed to its inhibition of proliferation, promotion of apoptosis of THP-1 cells by inhibition of the PI3K/Akt/mTOR signaling pathway. Given that matrine has been demonstrated to inhibit proliferation and induce apoptosis of THP-1 cells, matrine may be a useful candidate as a chemotherapeutic agent in the treatment of AML. 


\section{Acknowledgements}

Not applicable.

\section{Funding}

The present study was supported by the Nature Science Key Program of College and University of Anhui Province (grant no. KJ2018A0216).

\section{Availability of data and materials}

The analyzed data sets generated during the present study are available from the corresponding authors on reasonable request.

\section{Authors' contributions}

YH, NW and DL conceived and designed the study. NZ, HY and $\mathrm{YZ}$ were involved in data acquisition. $\mathrm{HX}, \mathrm{CZ}$ and $\mathrm{YZ}$ performed the data analysis. NZ, YH, YZ, NW and DL wrote the manuscript. All authors read and approved the final manuscript.

\section{Ethics approval and consent to participate}

The Ethics Committee of Bengbu Medical College (Bengbu, China) approved the study protocol.

\section{Patient consent for publication}

Not applicable.

\section{Competing interests}

The authors declare that they have no competing interests.

\section{References}

1. Döhner H, Weisdorf DJ and Bloomfield CD: Acute myeloid leukemia. N Engl J Med 373: 1136-1152, 2015.

2. Estey EH: Therapeutic options for acute myelogenous leukemia. Cancer 92: 1059-1073, 2001.

3. Jabo B, Morgan JW, Martinez ME, Ghamsary M and Wieduwilt MJ: Sociodemographic disparities in chemotherapy and hematopoietic cell transplantation utilization among adult acute lymphoblastic and acute myeloid leukemia patients. PLoS One 12: e0174760, 2017.

4. Kwong YL, Au WY, Chim CS, Pang A, Suen C and Liang R: Arsenic trioxide- and idarubicin-induced remissions in relapsed acute promyelocytic leukemia: Clinicopathological and molecular features of a pilot study. Am J Hematol 66: 274-279, 2001.

5. George B, Mathews V, Vishwabandhya A, Srivastava A and Chandy ML: Arsenic Trioxide (As2O3) in the treatment of patients with newly diagnosed acute promyelocytic leukemia (APML)-Toxicity and outcome. Blood 104: 889, 2004.

6. Lazo G, Kantarjian H, Estey E, Thomas D, O'Brien S and Cortes J: Use of arsenic trioxide (As2O3) in the treatment of patients with acute promyelocytic leukemia: The M.D. Anderson experience. Cancer 97: 2218-2224, 2003.

7. Zhou H, Xu M, Gao Y, Deng Z, Cao H, Zhang W, Wang Q, Zhang B, Song G, Zhan Y and $\mathrm{Hu} \mathrm{T}$ : Matrine induces caspase-independent program cell death in hepatocellular carcinoma through bid-mediated nuclear translocation of apoptosis inducing factor. Mol Cancer 13: 59, 2014.

8. Zhang Y, Zhang H, Yu P, Liu Q, Liu K, Duan H, Luan G, Yagasaki $\mathrm{K}$ and Zhang $\mathrm{G}$ : Effects of matrine against the growth of human lung cancer and hepatoma cells as well as lung cancer cell migration. Cytotechnology 59: 191-200, 2009.
9. Zhang S, Zhang Y, Zhuang Y, Wang J, Ye J, Zhang S, Wu J, Yu K and Han Y: Matrine induces apoptosis in human acute myeloid leukemia cells via the mitochondrial pathway and Akt inactivation. PLoS One 7: e46853, 2012.

10. Zhang LP, Jiang JK, Tam JW, Zhang Y, Liu XS, Xu XR, Liu BZ and $\mathrm{He}$ YJ: Effects of matrine on proliferation and differentiation in K-562 cells. Leuk Res 25: 793-800, 2001.

11. Yong-Qing Z, Gao-Sheng H and Hong-Jun L: Cells differential orientation in K562 cell line with matrine induction. J Oncol 10: 25-27, 2004.

12. Xu Q, Simpson SE, Scialla TJ, Bagg A and Carroll M: Survival of acute myeloid leukemia cells requires PI3 kinase activation. Blood 102: 972-980, 2003.

13. Kubota Y, Ohnishi H, Kitanaka A, Ishida T and Tanaka T: Constitutive activation of PI3K is involved in the spontaneous proliferation of primary acute myeloid leukemia cells: Direct evidence of PI3K activation. Leukemia 18: 1438-1440, 2004.

14. Dores GM, Devesa SS, Curtis RE, Linet MS and Morton LM: Acute leukemia incidence and patient survival among children and adults in the United States, 2001-2007. Blood 119: 34, 2012.

15. Krug U, Röllig C, Koschmieder A, Heinecke A, Sauerland MC, Schaich M, Thiede C, Kramer M, Braess J, Spiekermann K, et al: Complete remission and early death after intensive chemotherapy in patients aged 60 years or older with acute myeloid leukaemia: A web-based application for prediction of outcomes. Lancet 376: 2000-2008, 2010.

16. Gao HY, Li GY, Lou MM, Li XY, Wei XY and Wang JH: Hepatoprotective effect of Matrine salvianolic acid B salt on carbon tetrachloride-induced hepatic fibrosis. J Inflamm (Lond) 9: 16, 2012.

17. Chen JX, Shen HH, Niu M, Guo YM,Liu XQ, Han YZ,Zhang YM, Zhao YL, Bai BK, Zhou WJ and Xiao XH: Anti-hepatitis B virus effect of matrine-type alkaloid and involvement of p38 mitogen-activated protein kinase and tumor necrosis factor receptor-associated factor 6. Virus Res 215: 104-113, 2016.

18. Ma L, Zhu Z, Jiang L, Sun X, Lu X, Zhou M, Qian S and Li J: Matrine suppresses cell growth of human chronic myeloid leukemia cells via its inhibition of the interleukin-6/Janus activated kinase/signal transducer and activator of transcription 3 signaling cohort. Leuk Lymphoma 56: 2923-2930, 2015.

19. Yang Y, Guo JX, Shao ZQ and Gao JP: Matrine inhibits bladder cancer cell growth and invasion in vitro through PI3K/AKT signaling pathway: An experimental study. Asian Pac J Trop Med 10: 515-519, 2017.

20. Ishikawa Y: Genetic abnormalities in core binding factor acute myeloid leukemia. Rinsho Ketsuek (Japanese) 58: 991-998, 2017.

21. Illendula A, Pulikkan JA, Zong H, Grembecka J, Xue L, Sen S, Zhou Y, Boulton A, Kuntimaddi A, Gao Y, et al: Chemical biology. A small-molecule inhibitor of the aberrant transcription factor CBF $\beta$-SMMHC delays leukemia in mice. Science 347: 779-784, 2015.

22. Morgensztern D and Mcleod HL: PI3K/Akt/mTOR pathway as a target for cancer therapy. Anticancer Drugs 16: 797-803, 2005.

23. Jin R, Jin YY, Tang YL, Yang HJ, Zhou XQ and Lei Z: GPNMB silencing suppresses the proliferation and metastasis of osteosarcoma cells by blocking the PI3K/Akt/mTOR signaling pathway. Oncol Rep 39: 3034-3040, 2018.

24. Qi L, Sun K, Zhuang Y, Yang J and Chen J: Study on the association between $\mathrm{PI} 3 \mathrm{~K} / \mathrm{AKT} / \mathrm{mTOR}$ signaling pathway gene polymorphism and susceptibility to gastric cancer. J BUON 22: 1488-1493, 2017.

25. Tamburini J, Elie C, Bardet V, Chapuis N, Park S, Broët P, Cornillet-Lefebvre P, Lioure B, Ugo V, Blanchet O, et al: Constitutive phosphoinositide 3-kinase/Akt activation represents a favorable prognostic factor in de novo acute myelogenous leukemia patients. Blood 110: 1025-1028, 2007.

26. Park S, Chapuis N, Tamburini J, Bardet V, Cornilletlefebvre P, Willems L, Green A, Mayeux P, Lacombe C and Bouscary D: Role of the PI3K/AKT and mTOR signaling pathways in acute myeloid leukemia. Haematologica 95: 819-828, 2010.

27. Wu J, Hu G, Dong Y, Ma R, Yu Z, Jiang S, Han Y, Yu K and Zhang S: Matrine induces Akt/mTOR signalling inhibition-mediated autophagy and apoptosis in acute myeloid leukaemia cells. J Cell Mol Med 21: 1171-1181, 2017.

This work is licensed under a Creative Commons Attribution-NonCommercial-NoDerivatives 4.0 International (CC BY-NC-ND 4.0) License. 